\title{
Extramedullary Plasmacytoma Presenting as a Mediastinal Mass: A Comment
}

\section{Mediastende Kitle ile Beliren İlik Dışı (Ekstramedüller) Plazmositom: Bir Yorum}

\author{
Selami K. Toprak ${ }^{1}$, Sema Karakuş ${ }^{1}$, Pervin Topçuoğlu ${ }^{2}$ \\ ${ }^{1}$ Baskent University, School of Medicine, Department of Hematology, Ankara, Turkey \\ ${ }^{2}$ Ankara University, School of Medicine, Department of Hematology, Ankara, Turkey
}

\section{To the Editor,}

We read with great interest the recent publication about extramedullary plasmacytoma (EMP) by Shukla et al., in which they concluded that plasmacytoma involving the mediastinum is an early indication of the diagnosis of occult multiple myeloma (MM), which should be included in the differential diagnosis of mediastinal masses [1]. About 3\%-5\% of plasma cell neoplasms may present with isolated extramedullary involvement [2]. Because this disease can be confused with several malignancies-including lymphomas-microscopic and immunohistochemical evaluation are essential for accurate diagnosis $[3,4]$. We would like to share our experience concerning the refractory course of EMP.

A 62-year-old male presented in 2009 with a swollen left-anterior cervical lesion. MRI showed lytic lesions on several bony elements (suggestive of MM) and a plasmacytoma-like appearance of the swollen region. The patient's medical history was positive for similar swelling of the same region in 2000. The lesion was totally excised and diagnosed as EMP. Subsequently, the patient received radiation therapy (XRT) and the lesion remained silent for the following years. In 2009 he was diagnosed as stage II MM, subsequently given systemic chemotherapy, and had a very good partial response. The lesion persisted, decreasing in size by only 10\%. Although the patient's medical history and MRI findings were suggestive of the diagnosis, biopsy samples were histopathologically assessed to better establish the final status of the lesion, and showed fibrotic tissue remnants.

The patient underwent autologous hematopoietic stem cell transplantation (AHSCT) using high-dose melphalan. Urine immunofixation electrophoresis was positive during the front-line chemotherapy, but was negative post AHSCT. The treatment was considered successful in terms of MM response, but the lesion (thought to be a plasmacytoma) persisted, at 30\% of its original size. Our opinion-and that of several surgeons-was that any surgical intervention could lead to major life-threatening complications; therefore, routine outpatient follow-up provided.

MRI is a useful tool for evaluating the extent and size of EMP lesions; however, the role of MRI in staging EMP is not clear. Diagnosis of EMP is based on immunohistochemistry and the exclusion of a systemic plasma-cell proliferative disorder [5]. In the presented case, although not proven histopathologically, relapse and subsequent progression to MM, as is expected in 30\% of cases, occurred 9 years after the initial diagnosis. Interestingly, front-line high-dose chemotherapy resulted in an excellent MM response, similar success rates could not be obtained in terms of lesion size, which persisted with a lower than 50\% decrease. As EMPs are highly radiosensitive tumors, XRT alone is considered the treatment of choice, with local control rates of $80 \%-100 \%$ [5]. Yet, this treatment modal- 
ity requires a definitive diagnosis, which in the presented case was lacking due to biopsy sampling concerns. Relapse and progression to $\mathrm{MM}$ are the main concerns during the course of EMP. In 2000 the presented patient received only XRT following surgical excision of the lesion and did not receive adjuvant chemotherapy; however, given the lack of published evidence supporting its use in the management of EMP, this is acceptable [1]. Ahmed et al. reported a patient with an adrenal EMP that had a partial response to initial AHSCT and complete remission after repeat AHSCT [6]. Their case may also be an explanation for the merely $30 \%$ decrease in the lesion size in our case.

Although EMP has a relatively good prognosis and responds well to local treatment, adjuvant chemotherapy should be a consideration for the management of the disease. Additionally, EMP patients should remain under close lifelong observation, with yearly evaluation to rule out MM.

Written informed consent was obtained from the patient.

\section{Conflict of Interest Statement}

None of the authors has any conflicts of interest, including specific financial interests, relationships, and/or affiliations, relevant to the subject matter or materials included.

\section{References}

1. Shukla A, Bansal V, Bhutani R, Kumar G, Sharma J, Solanki S, Mehta A. Extramedullary plasmacytoma presenting as a mediastinal mass. Turk J Hematol 2011; 28: 228-231

2. Alexiou C, Kau RJ, Dietzfelbinger H, Kremer M, Spiess JC, Schratzenstaller B, Arnold W. Extramedullary plasmacytoma: Tumor occurrence and therapeutic concepts. Cancer 1999; $85 ; 2305-2314$

3. Boll M, Parkins E, O'Connor SJ, Rawstron AC, Owen RG. Extramedullary plasmacytoma are characterized by a 'myeloma-like' immunophenotype and genotype and occult bone marrow involvement. Br J Haematol 2010; 151 (5): $525-527$

4. Dimopoulos MA, Kiamouris C, Moulopoulos LA. Solitary plasmacytoma of bone and extramedullary plasmacytoma. Hematol Oncol Clin North Am 1999; 13 (6): 1249-1257

5. Vanan I, Redner A, Atlas M, Marin L, Kadkade P, Bandovic J, Jaffe ES. Solitary extramedullary plasmacytoma of the vocal cord in an adolescent. J Clin Oncol 2009; 27 (35): e244-247

6. Ahmed M, Al-Ghamdi A, Al-Omari M, Aljurf M, Al-Kadhi Y. Autologous bone marrow transplanation for extramedullary plasmacytoma presenting as adrenal incidentaloma. Ann Saudi Med 2009; 29 (3): 219-222 